\title{
EDITORIAL
}

\section{A complicated liaison: IL-33 and IL-33R in arthritis pathogenesis}

\author{
Thomas Kamradt* and Sebastian Drube \\ See related research by Martin et al., http://arthritis-research.com/content/15/1/R13
}

Abstract
Interruption of cytokine signaling, by targeting
either the cytokine itself or its cellular receptor, is a
mainstay in the therapy for patients with rheumatic
diseases. Interleukin (IL)-33, a member of the IL-1
cytokine family, has emerged as an important
mediator of inflammatory responses. In a side-by-
side examination of IL-33-deficient and IL-33 receptor
(IL-33R)-deficient mice in the K/BXN serum transfer
model, arthritis was ameliorated in the IL-33R knockout
(KO) mice but not in the IL-33 KO mice. These findings
complement previous knowledge on IL-33R signaling,
demonstrating that the IL-33R cross-activates other
signaling pathways in addition to IL-33-mediated
signals. The results reported by Martin and colleagues
in a previous issue of Arthritis Research \& Therapy
underline the clinical relevance of IL-33R cross-
signaling and further illustrate that targeting a cytokine
receptor (IL-33R) can have completely different clinical
outcomes than targeting the respective cytokine.

In a previous issue of Arthritis Research \& Therapy, Martin and colleagues [1] reported a puzzling finding: in a side-by-side comparison of interleukin-33 (IL-33)deficient mice and mice that lacked the receptor for IL-33 (IL-33R), K/BxN serum transfer arthritis was ameliorated only in the IL-33R-deficient but not the IL-33-deficient mice. IL-33 is an IL-1 family member that has emerged as a key regulator of protective and pathogenic immune responses [2,3]. It is also a chromatin-associated nuclear protein acting as a transcriptional regulator [2,3]. IL-33 is expressed by fibroblasts and epithelial, endothelial, mast, and innate immune cells. Similar to other IL-1 family members IL-33 signals through a heterodimeric complex

*Correspondence: immunologie@mit.uni-jena.de

Institut für Immunologie, Universitätsklinikum Jena, Leutragraben 3, 07743 Jena, Germany consisting of the binding receptor (T1/ST2) and the IL-1R accessory protein (IL-1RAcP) [2,3]. T1/ST2 occurs in membrane-bound or soluble (sIL-33R) isoforms. Expression of membrane-bound IL-33R is restricted to hematopoietic cells, most prominently in $\mathrm{T}$ helper 2 (Th2) lymphocytes, mast cells, eosinophils, basophils, and innate lymphoid cells. Signaling via IL-33R is relevant in type 2 immune responses as it induces the expression of IL-4, IL-5, and IL-13 in Th 2 lymphocytes, independently of T-cell receptor triggering [4]. Soluble T1/ST2 functions as a decoy receptor that can block IL-33/IL-33R interaction $[2,3]$.

IL-33 is expressed in the synovium of patients with rheumatoid arthritis (RA), and IL-33 serum concentrations are elevated in patients with RA [3]. These findings suggest that IL-33 is involved in RA pathogenesis. This concept is supported by data obtained in collageninduced arthritis (CIA). Treatment with a monoclonal antibody against T1/ST2 or genetic ablation of T1/ST2 ameliorated arthritis [5,6]. In contrast, injection of IL-33 exacerbated CIA [6].

IL-33 and IL-33R have also been studied in the human tumor necrosis factor-alpha transgenic [7] and the K/ BxN serum transfer models of arthritis. It was reported, in line with the conclusions from the CIA model, that K/ BxN serum transfer arthritis was ameliorated in IL-33R (T1/ST2) knockout (KO) mice [8]. As expected from this finding, injection of IL-33 exacerbated $\mathrm{K} / \mathrm{BxN}$ serum transfer arthritis [8]. Another study, however, yielded contradicting findings. There, the injection of IL-33 ameliorated $\mathrm{K} / \mathrm{BxN}$ serum transfer arthritis and this was dependent on IL-4 signaling [9].

It is against this background that Martin and colleagues [1] aimed to compare the contributions of IL-33 and its receptor directly within the same model $(\mathrm{K} / \mathrm{BxN}$ serum transfer) in the same laboratory. The authors found both the incidence and severity of arthritis to be reduced in ST2 KO mice in comparison with wild-type (WT) controls. In striking contrast, arthritis incidence and severity did not differ in IL-33 KO mice and WT mice. Moreover, the authors found that sT1/ST2, the decoy receptor for IL-33, had no effect on arthritis [1]. 
How can these contradictory findings be explained? Mouse models of inflammatory diseases, including arthritis, are sometimes affected by environmental factors such as the different microbial colonization of experimental animals in different animal facilities. By performing the experiments in IL-33 and IL-33R KO mice within one group and the same facilities, Martin and colleagues could rule out such explanations for their findings. The il- $33^{-/-}$and $\mathrm{t} 1 / \mathrm{st} 2^{-/-}$mice were made from genetically modified embryonic stem cells of the $129 / \mathrm{Sv}$ mouse strain and then back-crossed to C57BL/6 mice, in which the experiments were performed. Martin and colleagues used a 377 SNIP panel to determine that the il-33-1- mice were $100 \% \mathrm{C} 57 \mathrm{BL} / 6$. In contrast, the $\mathrm{t} 1 / \mathrm{st} 2^{-/-}$mice shared only $89 \%$ of 55 tested markers with the C57BL/ 6 mice that were used as WT controls [1]. The possibility, therefore, remains that subtle genetic polymorphisms may form the basis for the observed differences [10]. An obvious solution to this problem is to use littermate controls for each genetically modified strain [10].

Alternative explanations for the opposite findings in il- $33^{-/-}$and $\mathrm{t} 1 / \mathrm{st} 2^{-/-}$mice stem from the IL-1R family signaling pathways. IL-1R family members share the IL-1RAcP. It is, therefore, conceivable that, in the absence of one receptor (for example, T1/ST2), the formation of other receptor complexes (IL-1R1/IL-1RAcP and IL-18R $\alpha$ / IL-1RAcP) is increased, allowing enhanced IL-1 or IL-18 signaling. In fact, macrophages from T1/ST2-deficient mice were reported to produce more proinflammatory cytokines than cells from WT mice in response to IL-1 or lipopolysaccharide [11]. Both CIA and $\mathrm{K} / \mathrm{BxN}$ arthritis depend on IL-1 [12]. Increased responsiveness toward IL-1 would be expected to increase incidence and severity of arthritis. Therefore, enhanced formation of other receptor complexes is unlikely to explain why mice lacking $\mathrm{T} 1 / \mathrm{ST} 2^{-/-}$are protected from arthritis whereas IL-33-/- mice are susceptible [1].

Earlier findings from other disease models resemble those reported by Martin and colleagues [1] and have been reported for IL-18, another IL-1 family member, and its receptor. IL-18R $\alpha$-deficient mice were resistant to experimental autoimmune encephalomyelitis, a mouse model for multiple sclerosis. In contrast, IL-18-deficient mice were susceptible to experimental autoimmune encephalomyelitis [13]. The published data on the role of IL-33 and T1/ST2 in Leishmania infection allow the conclusion that $\mathrm{T} 1 / \mathrm{ST}_{2}{ }^{+}$effector cells, but not IL-33induced signaling, are relevant for disease pathogenesis [3]. Consequently, T1/ST2 may exert functions in addition to the transduction of IL-33-induced signals.

We found that IL-33-induced signaling via T1/ST2 cross-activates the receptor tyrosine kinase c-Kit, the receptor for stem cell factor in human and murine mast cells. T1/ST2-induced activation of $\mathrm{c}-\mathrm{Kit}$ is required to elicit optimal effector functions in response to IL-33 [14]. The structural basis for this cross-activation is the ligandinduced complex formation between c-Kit, T1/ST2, and IL-1R accessory protein (IL-1RAcP). The requirement for T1/ST2 for optimal signal transduction from other receptors could provide one mechanistic explanation for the fact that T1/ST2-deficient mice, but not IL-33deficient mice, are protected from arthritis. Together with the data reported by Martin and colleagues [1], these findings indicate that targeting IL-33 or its receptor might result in fundamentally different outcomes in patients (with arthritis).

To date, the cross-activation of c-Kit by T1/ST2 has been reported [14]. Mast cells are probably involved in arthritis pathogenesis, but most cell lineages relevant for arthritis pathogenesis do not express c-Kit. It remains to be elucidated whether T1/ST2 cooperates with other receptor tyrosine kinases in other effector cells that do not express c-Kit. A detailed understanding of such interactions between T1/ST2 with other signaling pathways seems to be mandatory for rational therapeutic manipulation of this system. More surprises, in addition to the puzzling findings reported by Martin and colleagues [1], regarding T1/ST2 signaling in health and disease are likely to be discovered.

\section{Abbreviations}

CIA, collagen-induced arthritis; IL, interleukin; IL-33R, interleukin-33 receptor; IL-1RAcP, interleukin-1 receptor accessory protein; KO, knockout; RA, rheumatoid arthritis; Th2, T helper 2;WT, wild-type.

\section{Competing interests}

The authors declare that they have no competing interests.

Published: 2 May 2013

\section{References}

1. Martin P, Talabot-Ayer D, Seemayer CA, Vigne S, Lamacchia C, Rodriguez E, Finckh A, Smith DE, Gabay C, Palmer G: Disease severity in K/BxN serum transfer-induced arthritis is not affected by IL-33 deficiency. Arthritis Res Ther 2013, 15:R13.

2. Smith DE: The biological paths of IL-1 family members IL-18 and IL-33. J Leukoc Biol 2011, 89:383-392

3. Oboki K, Ohno T, Kajiwara N, Saito H, Nakae S: IL-33 and IL-33 receptors in host defense and diseases. Allergol Int 2010, 59:143-160.

4. Meisel C, Bonhagen K, Löhning M, Coyle AC, Guttierez-Ramos JC, Radbruch A, Kamradt T: Regulation and function of T1/ST2-expression on CD4 ${ }^{+} \mathrm{T}$ cells: induction of type 2 cytokine production by T1/ST2-crosslinking. J Immunol 2001, 166:3143-3150.

5. Palmer G, Talabot-Ayer D, Lamacchia C, Toy D, Seemayer CA, Viatte S, Finckh A, Smith DE, Gabay C: Inhibition of interleukin-33 signaling attenuates the severity of experimental arthritis. Arthritis Rheum 2009, 60:738-749.

6. Xu D, Jiang HR, Kewin P, Li Y, Mu R, Fraser AR, Pitman N, Kurowska-Stolarska M, McKenzie AN, McInnes IB, Liew FY: IL-33 exacerbates antigen-induced arthritis by activating mast cells. Proc Natl Acad Sci U S A 2008, 105:10913-10918.

7. Zaiss MM, Kurowska-Stolarska M, Böhm C, Gary R, Scholtysek C, Stolarski B, Reilly J, Kerr S, Millar NL, Kamradt T, McInnes IB, Fallon PG, David JP, Liew FY, Schett G: IL-33 shifts the balance from osteoclast to alternatively activated macrophage differentiation and protects from TNF-alpha-mediated bone loss. J Immuno/ 2011, 186:6097-6105.

8. Xu D, Jiang HR, Li Y, Pushparaj PN, Kurowska-Stolarska M, Leung BP, Mu R, Tay HK, McKenzie AN, McInnes IB, Melendez AJ, Liew FY: IL-33 exacerbates 
autoantibody-induced arthritis. J Immuno/ 2010, 184:2620-2626.

9. Anthony RM, Kobayashi T, Wermeling F, Ravetch JV: Intravenous gammaglobulin suppresses inflammation through a novel $\mathrm{T}(\mathrm{H}) 2$ pathway. Nature 2011, 475:110-113.

10. Holmdahl R, Malissen B: The need for littermate controls. Eur J Immunol 2012, 42:45-47.

11. Brint EK, Xu D, Liu H, Dunne A, McKenzie AN, O'Neill LA, Liew FY: ST2 is an inhibitor of interleukin 1 receptor and Toll-like receptor 4 signaling and maintains endotoxin tolerance. Nat Immunol 2004, 5:373-379.

12. Kamradt T, Schubert D: The role and clinical implications of G6PI in experimental models of rheumatoid arthritis. Arthritis Res 2005, 7:20-28.

13. Gutcher I, Urich E, Wolter K, Prinz M, Becher B: Interleukin 18-independent engagement of interleukin 18 receptor-alpha is required for autoimmune inflammation. Nat Immuno/ 2006, 7:946-953.

14. Drube S, Heink S, Walter S, Löhn T, Grusser M, Gerbaulet A, Berod L, Schons J, Dudeck A, Freitag J, Grotha S, Reich D, Rudeschko O, Norgauer J, Hartmann K, Roers A, Kamradt T: The receptor tyrosine kinase c-Kit controls IL-33 receptor signaling in mast cells. Blood 2010, 115:3899-3906.

doi:10.1186/ar4209

Cite this article as: Kamradt T, Drube S: A complicated liaison: IL-33 and IL-33R in arthritis pathogenesis. Arthritis Research \& Therapy 2013, 15:115. 